\title{
FIELD-INTENSITY MEASUREMENTS AT FREQUENCIES FROM 285 TO 5,400 KILOCYCLES PER SECOND
}

\author{
By S. S. Kirby and K. A. Norton
}

ABSTRACT

Radio field intensities were measured at distances of only a few wave lengths from a transmitting station on a wide range of frequencies, including the broadcast band, in order to determine the distance at which ground absorption became appreciable. At a distance of $2.4 \mathrm{~km}$, there was no appreciable absorption for frequencies below about $1,000 \mathrm{kc}$; above this frequency, the absorption became appreciable and increased as the frequency was increased. Daylight measurements made at greater distances on broadcast transmissions, airways phones and airways beacons show that field intensities fall off to 1 per cent of what the inverse distance law with no absorption would give at distances from 100 to $400 \mathrm{~km}$, depending on the frequency and the nature of the ground. The experimental data were compared with Rolf's attentuation graphs in order to determine the electrical constants of the land east and west of the Allegheny Mountains. East of and including the mountains (Maryland, Pennsylvania, and New Jersey) the conductivity and dielectric constant were found to be $3.35 \times 10^{-14}$ e.m.u. and 13 , respectively; west of the mountains (near Chicago) they were found to be $1.07 \times 10^{-13}$ e.m.u. and 13 , respectively. Using these constants theoretical values of field intensity were graphed for these two types of ground and for broadcasting frequencies.

The experimental data were also compared with results given by the AustinCohen transmission formula. It was found that for overland transmission in the range of frequencies observed this formula did not satisfactorily give the variations in field intensity as the distance was changed or as the frequency was changed.

The measurements reported in this paper are part of a research on the accuracy of means of measurement of radio field intensity. Measurements of received field intensities at broadcasting frequencies, at a distance of about $3 \mathrm{~km}$ from a radio transmitting station, were compared with values calculated from the simple radio transmission formula. Let $F_{m}$ represent the measured value of field intensity and $F_{c}$ the value calculated from the simple transmission formula in which the earth is assumed to be perfectly conducting. It was found that the ratio $\frac{F_{m}}{F_{c}}$ decreased at this distance as the frequency increased. The transmission formula used was the familiar inverse distance formula

$$
F_{c}=\frac{377 h f I}{c d} \mathrm{volts} / \mathrm{cm}
$$

where

$h=$ the effective height of transmitting antenna in centimeters.

$f=$ the frequency in cycles per second.

$I=$ current in transmitting antenna measured in amperes.

$c=$ velocity of propagation of electromagnetic waves $\left(3 \times 10^{10}\right.$ $\mathrm{cm} / \mathrm{sec}$.)

$d=$ distance in centimeters from transmitter to the point at which the field intensity was measured. 
The field intensities were measured with a commercial field intensity measuring set, which had been checked against measuring sets constructed by the bureau. The transmitting antenna used was a condenser antenna $114 \mathrm{~cm}$ high and $750 \mathrm{~cm}$ radius. The value used for $h$ was the actual distance between the plates of this arrangement. The transmission path was almost entirely over river water, the transmitting and receiving stations being located on opposite shores of the Potomac River. The fact that the ratio $F_{m} / F_{c}$ decreased as the frequency increased was interpreted to mean that there was an appreciable absorption at these frequencies over even this short path. These observations were checked with a vertical wire antenna and a loop antenna with similar results.

In order to check the conclusion that absorption was appreciable over distances of a few kilometers at broadcast frequencies the field

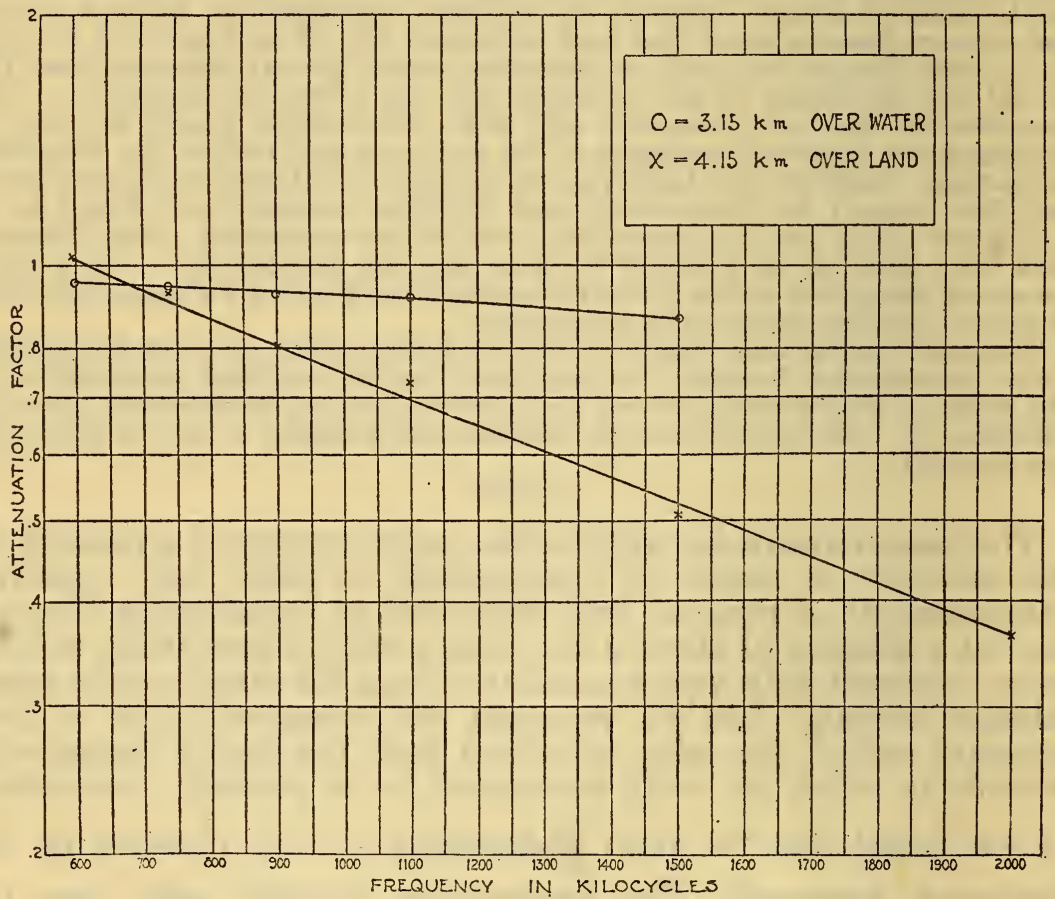

FIGURE 1.-Attenuation factors versus frequency

(The upper one for $d=3.15 \mathrm{~km}$ over fresh water and the lower one for $d=4.15 \mathrm{~km}$ over land.)

intensity measuring set was put on a boat so that its distance from the transmitter could be varied in a straight line and so as to obtain uniform ground conditions. The transmitter was set at the water's edge at low tide and was over water at high tide. A loop antenna was used with the transmitter in this case. Measurements were made at distances of 1 to 2 wave lengths and at the distance of $3.15 \mathrm{~km}$ (corresponding to 5 to 16 wave lengths) from the transmitting station. The ratio of $F_{m} / F_{c}$ at the greater distance was divided by that ratio at the nearer distance to get the "attenuation factor" $A$ which we define as

$$
A=\frac{F d}{F_{1} d_{1}}
$$


where $F_{1}$ is the field intensity measured at a distance $d_{1}$ kilometers which is so near the transmitter that absorption has not yet become appreciable, and $F$ is the measured field intensity at any greater distance $d$ kilometers. All conditions at the transmitter (that is, antenna current, tide, frequency, etc.) are the same when these two measurements are made. The results of these measurements are shown by the upper graph of Figure 1. The lower graph of Figure 1 shows attenuation factors obtained in a similar manner over a land path of $4.15 \mathrm{~km}$.

The ratios of $F_{m} / F_{c}$ (not $A$ ) were also determined for eight different distances over the water path and for several different frequencies from 590 to $5,400 \mathrm{kc}$. The results of these measurements are shown in Figure 2. For frequencies up to $1,100 \mathrm{kc}$ no appreciable absorption could be detected at distances up to $2.4 \mathrm{~km}$. The accuracy of the measurements was about 5 per cent and ratios differing from unity by

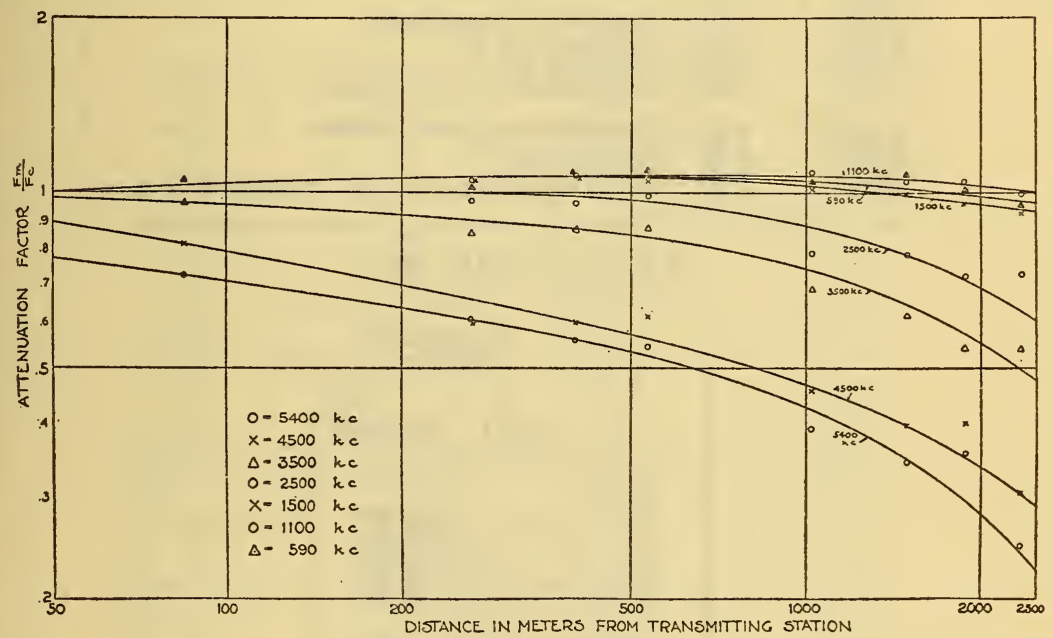

FIgURE 2.-Attenuation factor $F_{m} / F_{c}$ versus distance for various frequencies with a water path

(Graphs are not theoretical as are some of the later graphs.)

less than this amount indicated no appreciable absorption. At higher frequencies the absorption became appreciable and increased as the frequency increased.

The results of these two experiments showed that if field intensity measurements were made around a transmitting station to determine the actual radiation, they should be made fairly close to the transmitter, say within 5 wave lengths, for frequencies in the broadcast band, in order to avoid errors due to absorption. The maximum distances at which such measurements should be made depend on the nature of the transmission path. Over highly conducting ground such measurements could be made farther from the transmitting station than over poorly conducting ground.

Later daytime field intensity measurements were made of transmissions from 12 broadcasting stations, 3 airways phones, 1 airways radio range beacon, and the Bureau of Standards experimental beacon, at various distances, from 1 to $3 \mathrm{~km}$ out to several hundred kilometers from the transmitting station. Usually the near-by measurements 
were taken within the distance at which absorption began as was determined by Figures 1 and 2 . Two trips were made with a field intensity measuring set in a laboratory truck. The first trip was made June 2 to 7, 1930, over path No. 1 as shown in Figure 3. The second trip was made November 3 to 19,1930 , over paths 2,3 , and 4 . The stations measured were:

\begin{tabular}{|c|c|c|}
\hline Station & Frequency & Location \\
\hline $\begin{array}{l}\text { WWV } \\
\text { WWU } \\
\text { WWO } \\
\text { KDA }\end{array}$ & $\begin{array}{r}k c \\
290 \\
338 \\
344 \\
350\end{array}$ & $\begin{array}{l}\text { College Park, Md., near Washington. } \\
\text { New Brunswick, N. J. } \\
\text { Cleveland, Ohio. } \\
\text { Maywood, Ill., near Chicago. }\end{array}$ \\
\hline $\begin{array}{l}\text { WMAL } \\
\text { WMAQ } \\
\text { WGN } \\
\text { WJZ }\end{array}$ & $\begin{array}{l}\lceil 630 \\
670 \\
720 \\
760\end{array}$ & $\begin{array}{l}\text { Washington, D. C. } \\
\text { Addison, III., near Chicago. } \\
\text { Elgin, Ill. } \\
\text { Bound Brook, N. J. }\end{array}$ \\
\hline $\begin{array}{l}\text { WBBM } \\
\text { WRC } \\
\text { KDKA } \\
\text { KYW }\end{array}$ & $\begin{array}{r}770 \\
950 \\
980 \\
1,020\end{array}$ & $\begin{array}{l}\text { Glenview, Ill., near Chicago. } \\
\text { Washington, D. C. } \\
\text { Pittsburgh, Pa. } \\
\text { Bloomingdale, ill., near Chicago. }\end{array}$ \\
\hline $\begin{array}{l}\text { WTAM } \\
\text { WOWO } \\
\text { WHK } \\
\text { WJSV }\end{array}$ & $\begin{array}{l}1,070 \\
1,160 \\
1,390 \\
1,460\end{array}$ & $\begin{array}{l}\text { Brecksville, Ohio, near Cleveland. } \\
\text { Fort Wayne, Ind. } \\
\text { Cleveland, Ohio. } \\
\text { Mount Vernon Hills, Va., near Washington, D. C. }\end{array}$ \\
\hline
\end{tabular}

TABLE 1.-WGN, 720 kc

\begin{tabular}{|c|c|c|}
\hline \multirow{2}{*}{$D$} & \multicolumn{2}{|c|}{$\begin{array}{l}\text { Field intensity } \\
\mu V / \text { meter }\end{array}$} \\
\hline & Going & Returning \\
\hline $\begin{array}{l}k m \\
3.86 \\
13 \\
29 \\
36.5 \\
45.7\end{array}$ & & $\begin{array}{r}356,000 \\
124,900 \\
49,950 \\
34,000 \\
25,200\end{array}$ \\
\hline $\begin{array}{r}61.5 \\
78.5 \\
92.0 \\
109.3 \\
131\end{array}$ & 8,650 & $\begin{array}{r}14,595 \\
8,720 \\
7,140 \\
4,010 \\
1,854\end{array}$ \\
\hline $\begin{array}{l}150 \\
192.5 \\
243 \\
281 \\
326\end{array}$ & $\begin{array}{l}1,192 \\
600 \\
317.5 \\
237.0 \\
183.9\end{array}$ & $\begin{array}{r}1,269 \\
614 \\
318 \\
230 \\
184\end{array}$ \\
\hline $\begin{array}{l}375 \\
414 \\
456 \\
492\end{array}$ & $\begin{array}{r}146.1 \\
89.5 \\
61.9 \\
54.7\end{array}$ & $\begin{array}{r}155 \\
87.8 \\
61.1 \\
\end{array}$ \\
\hline $\begin{array}{l}496 \\
513 \\
532 \\
595\end{array}$ & 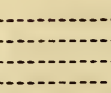 & $\begin{array}{r}36.7 \\
43.4 \\
23.4 \\
9.6\end{array}$ \\
\hline
\end{tabular}

The field-intensity measurements made on these trips are plotted on Figures 4 to 10, inclusive. In order to give some idea of the variations in the field intensities from day to day the measurements made on station WGN are listed in Table 1. It may be seen that the measurements on the trip into Chicago agree very well with those made on the trip out of Chicago. It may be of some interest to men- 


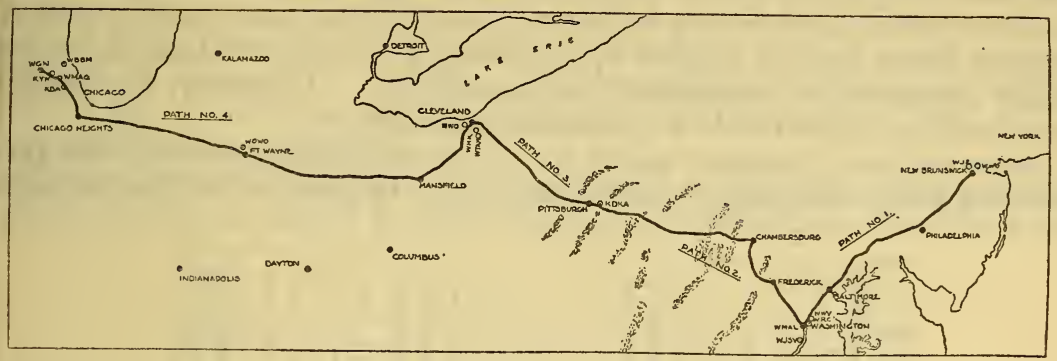

FIGURE 3.-Paths over which field-intensity measurements were made of transmissions from broadcasting and airways stations

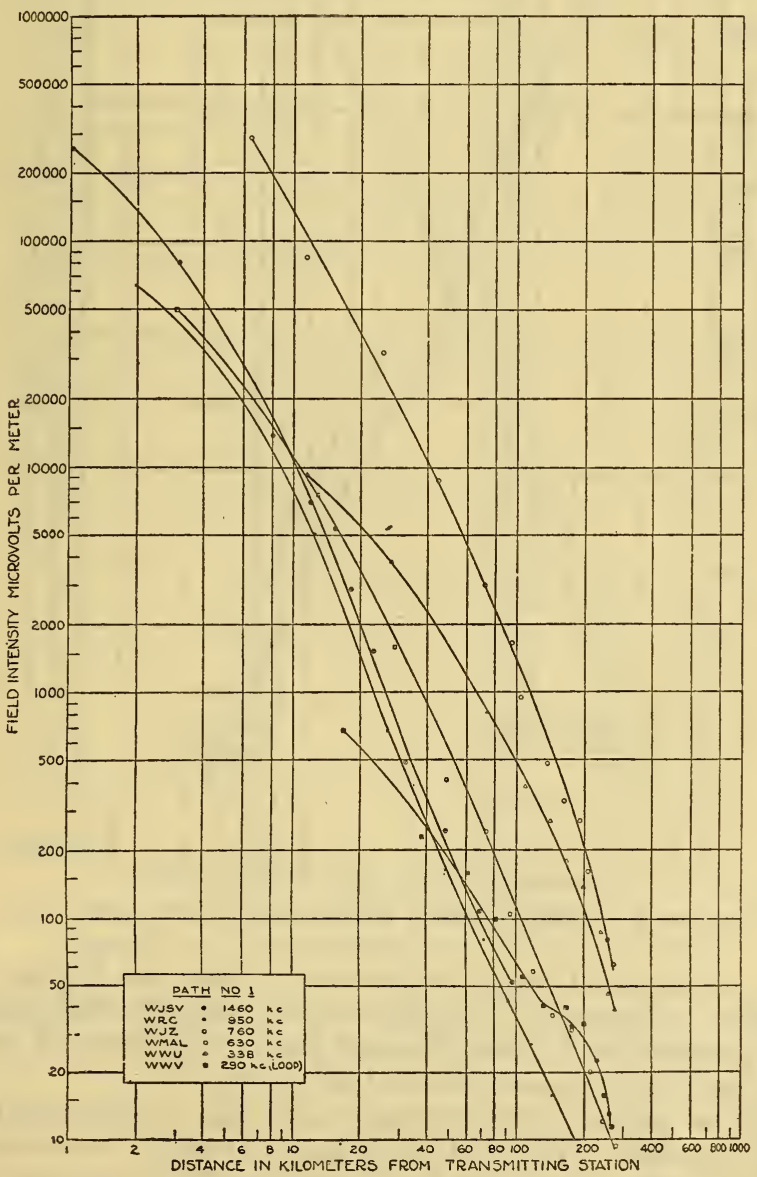

FIGURE 4.-Field-intensity measurement over path No. 1 
tion at this point that the field intensities were not calculated from the data until the trip was finished. This allowed some irregularities to enter the measurements which might otherwise have been avoided, because there was no further opportunity to check and find the cause of any apparently inconsistent measurements. However, the results are now much less liable to psychological errors.

Some points of interest stand out on these graphs, notably the fact that the lower frequency transmissions, as illustrated by the airways

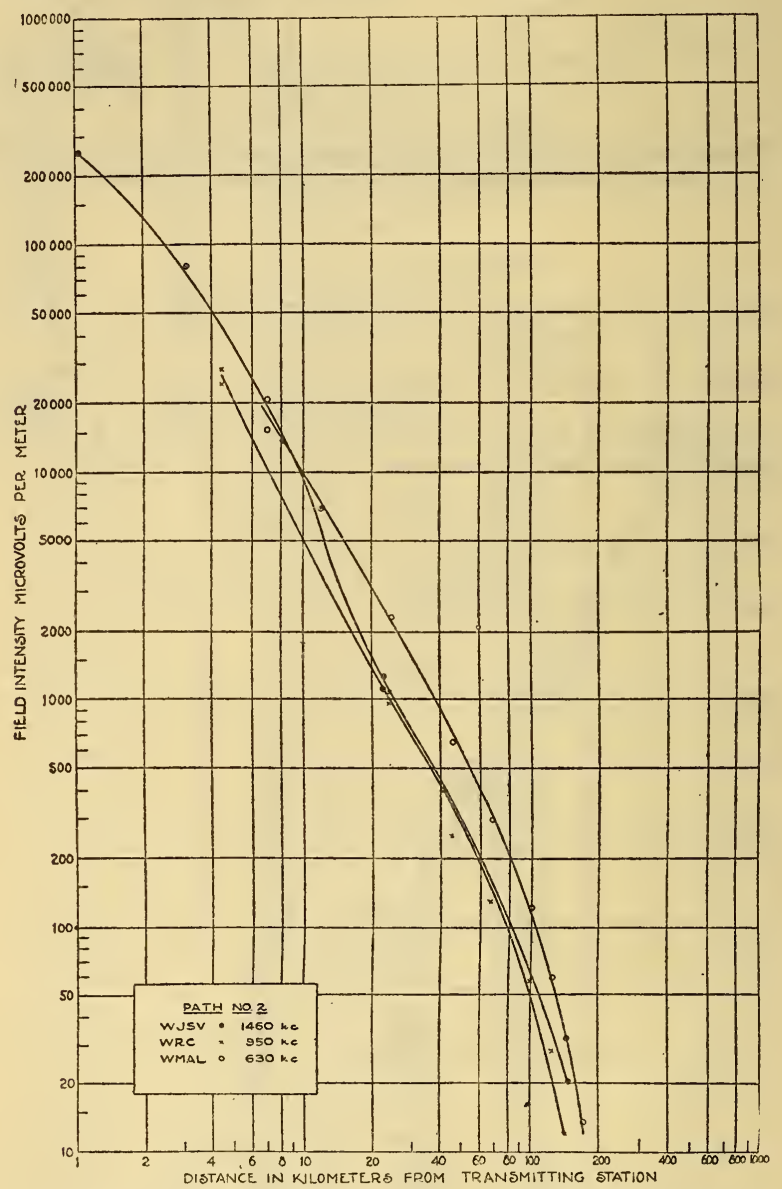

Frgure 5.-Field-intensity measurements over path No. 2

phones, are attenuated much more slowly than the higher frequency transmissions. However, it is difficult to compare the absorption at various frequencies and over different paths by means of such graphs because the radiated power differed so much.

It should be noted at this point that the attenuation factor as defined by equation (2) is independent of the power used by the transmitting station provided the same power is radiated when the measurement at $d$ is made as when the measurement at $d_{1}$ is made. The stations measured usually maintained their antenna current at a fairly constant value during the measurements and consequently 
the values of $A$ may be considered to represent the average characteristics of a radio-transmission path for any given frequency. These values of $A$ for most of the experimental results described are determined from the measurements by means of equation (2) and are plotted in Figures 11 to 16 . The experimental results are represented by the points plotted; the graphs are theoretical and will be discussed in the following:

In the past various attempts have been made to develop a theory which would be useful in predicting the attenuation of radio waves

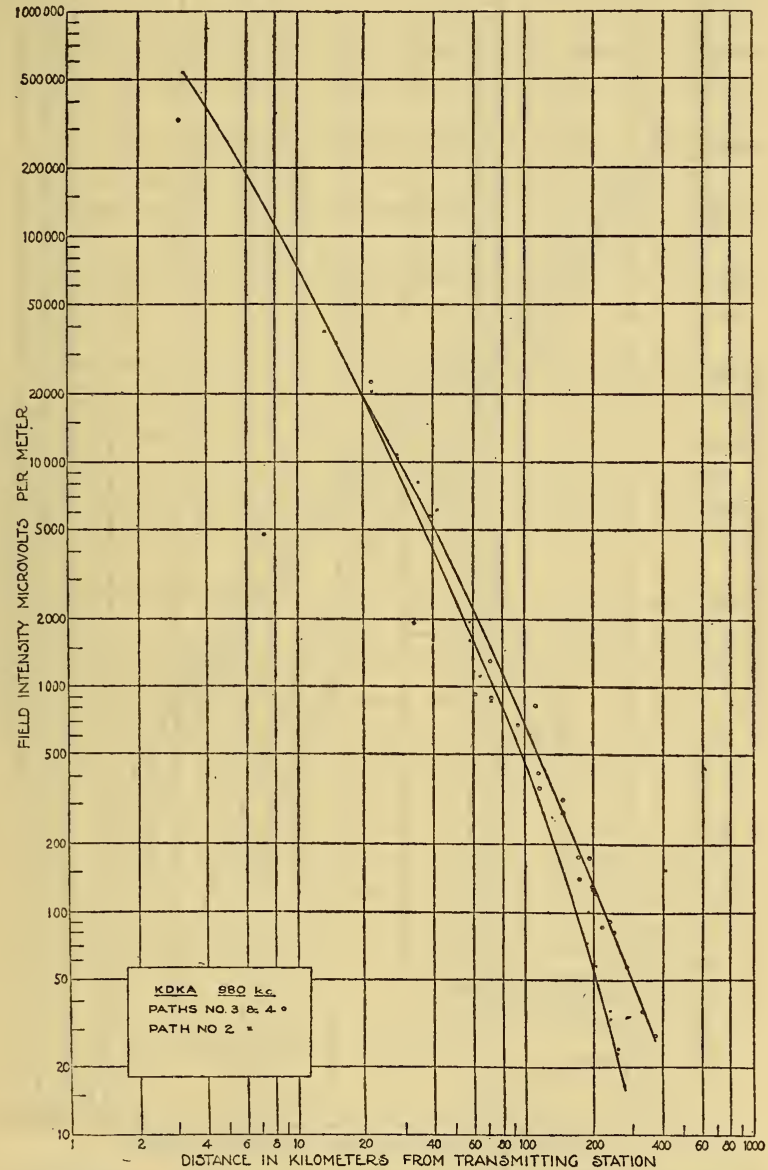

FIGURE 6.-Field intensities for $K D K A$ on $980 \mathrm{kc}$

along the surface of the earth. In 1909 Sommerfeld published his paper The Propagation of Waves in Wireless Telegraphy. ${ }^{1}$ However, the analysis was quite involved and very little use was made of it until in recent years. In 1911, the empirical Austin-Cohen formula ${ }^{2}$ was published. The data on which it is based were obtained in the daytime over sea water and for frequencies less than 1,000 kc and for

1 Ann. d. Physik (4), vol. 28, pp. 665 to 736, 1909.

2 L. W. Austin, Some Quantitative Experiments in Long Distance Radiotelegraphy, B. S. Sci. Paper No. 159. B. S. Bull., vol. 7, No. 3, p. 315. 1911. 
distances up to $1,900 \mathrm{~km}$. Since it was published it has been used quite extensively for over land as well as over water paths and over a wide range of frequencies and distances. It should be emphasized that many of these conditions were far different from those for which the Austin-Cohen formula was derived. No evidence which contradicts this formula for the conditions under which it was derived is presented in this paper. We do, however, present data which show that this formula is not usable for overland transmissions at broad-

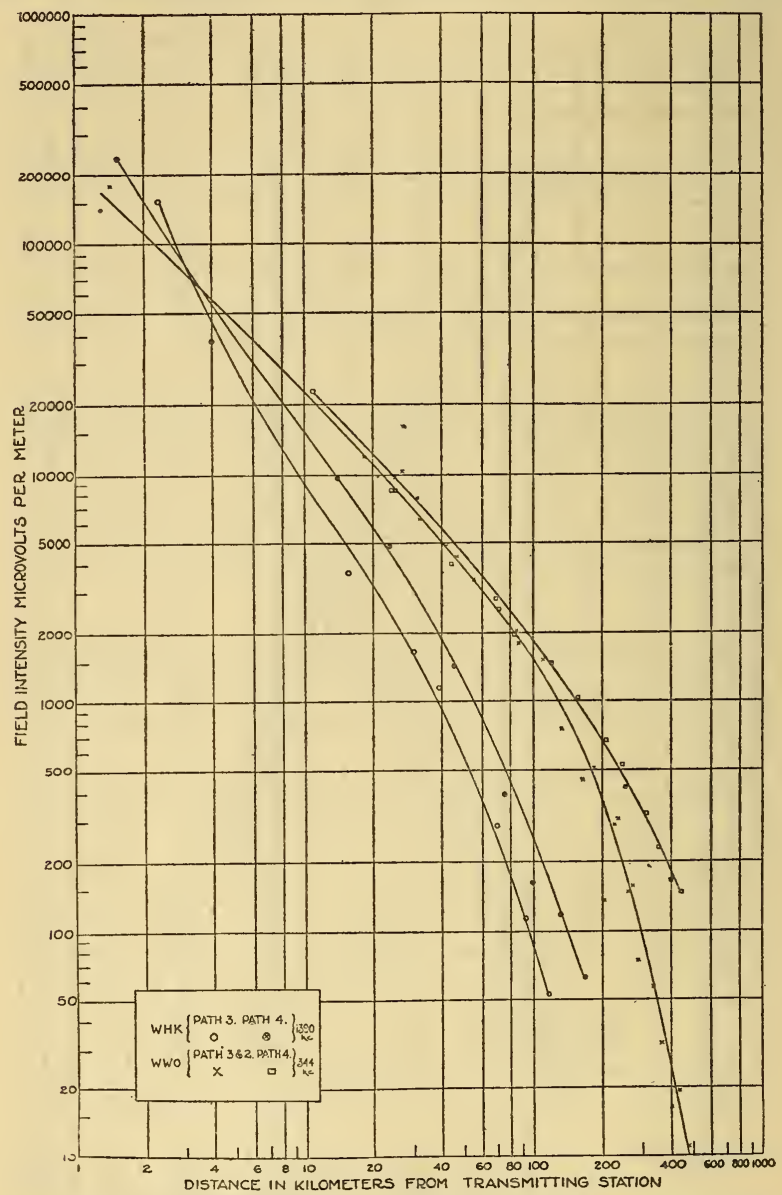

FIgURE 7.-Field-intensity measurements for paths Nos. 3 and 4

cast frequencies. Our data also indicate that, in the absence of downcoming waves, the Sommerfeld theory represents the facts fairly well.

In the Austin-Cohen formula the attenuation factor is given by

$$
A=e^{-\alpha \sqrt{f} D}
$$

$f=$ frequency in kilocycles per second.

$D=$ distance from transmitting station in kilometers. 
If a formula of this type correctly represented the law of decay, it would be possible to determine an $\alpha$ for any given radio-transmission path (supposed electromagnetically homogeneous) which would then determine the proper attenuation factors at any point of the path and for any frequency. From our experimentally determined values of $A$ (see equation (2)), a value of $\alpha$ is determined for each measurement made by substituting in equation (3). The values of $\alpha$ so determined for the measurements on path No. 1 are given in Table 2. These values are then averaged giving a value of $\alpha=0.00116$, which should

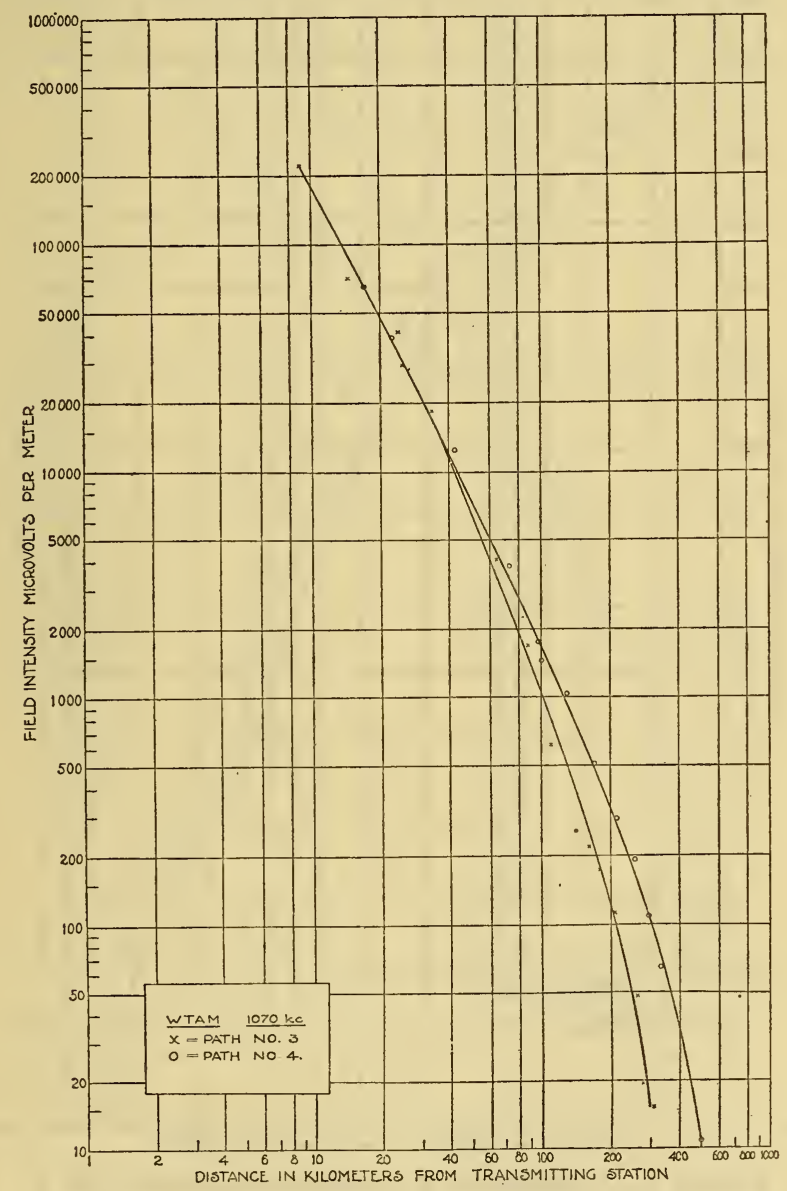

Frgure 8.-Field intensities for WTAM on 1,070 kc

represent the absorption characteristics of this path. Using this value of $\alpha$ in equation (3) the attenuation graphs are determined for 290 , 338,760 , and 1,460 kc and are plotted in the dotted graphs of Figures 11 and 12 . It may be seen that the experimental points do not fit the graphs, in some cases the points are twenty-four times too far above the graphs, while in other cases the graphs are 3.5 times too far above the points. Similar errors would be indicated if the formula was plotted for the other paths using the average values of $\alpha$ as determined from our measurements. The average value of $\alpha$ used to plot 
these graphs might be questioned because the values of $\alpha$ determined from the field intensity varied both with the distance and with the frequency. However, it may be seen from Figures 11 and 12 that such graphs would not fit the experimental data for any value of $\alpha$ chosen; the graphs do not have the proper curvature, thus giving incorrect attenuation factors as the distance is varied, and they do not have enough separation to give proper attenuation factors as the frequency varies. We thus see that for this range of frequencies and for land paths, another formula must be used.

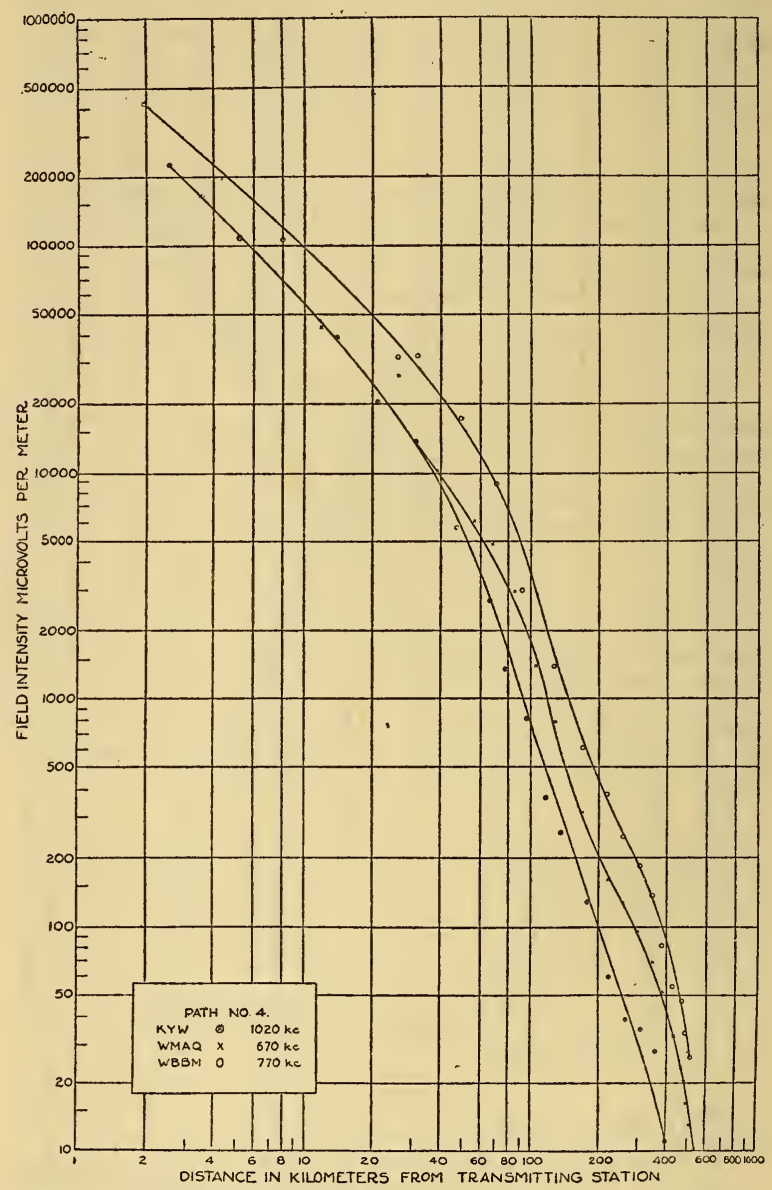

Figdre 9.-Field-intensity measurements on path No. 4

This is offered by the Sommerfeld theory for which graphs have been made by Bruno Rolf. ${ }^{3}$ These graphs apply to ground wave transmission only. Sommerfeld obtained the solution by determining the propagation along the plane surface bounding regions (air and earth) of conductivity $\sigma_{1}$ and $\sigma_{2}$, dielectric constant $\epsilon_{1}$ and $\epsilon_{2}$, and permeability $\mu_{1}$ and $\mu_{2}$. Rolf has graphed the values of $A$ for the case, $\sigma_{1}=0, \epsilon_{1}=1, \mu_{1}=\mu_{2}=1$, while $\epsilon_{2}$ and $\sigma_{2}$ are variable and represent the earth constants for the particular path involved. Thus we see 
that our problem becomes one of determining the average values of the radio-frequency dielectric constant and conductivity of the ground for the various paths over which measurements were made. The method of determining these was that described by Rolf.

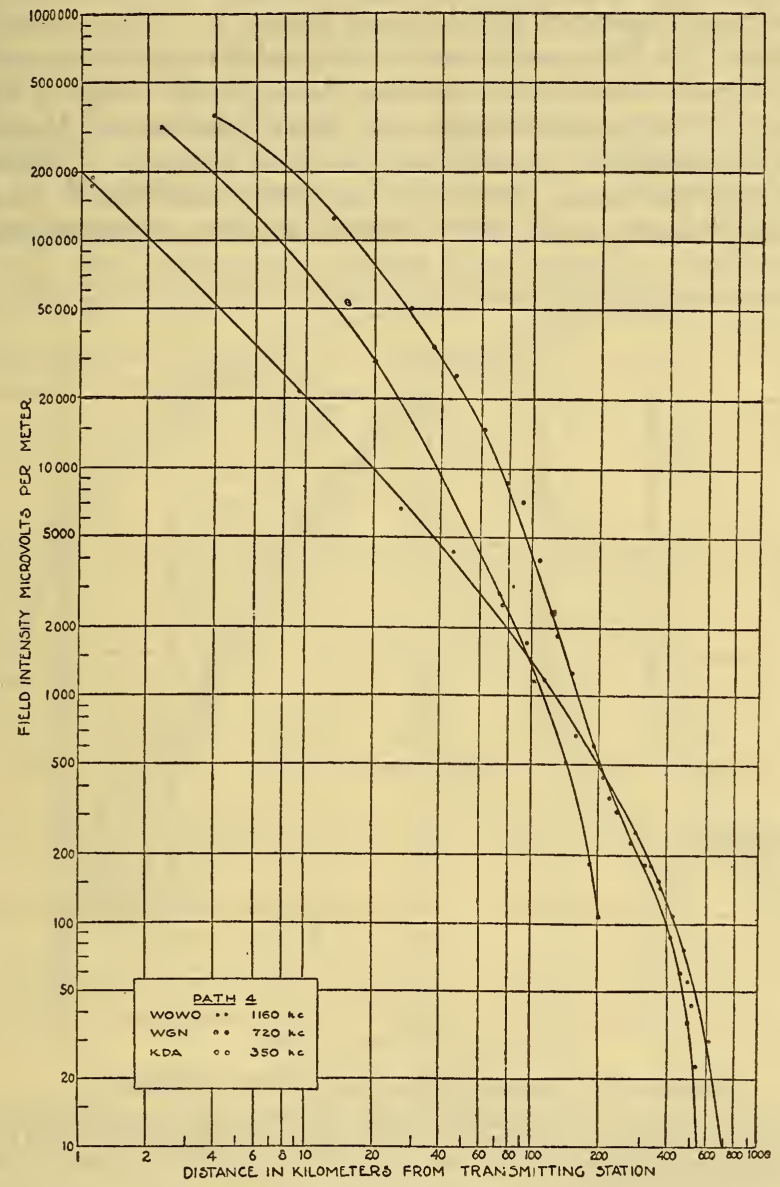

Figdre 10.-Field-intensity measurements on path No. 4

TABLE 2

\begin{tabular}{|c|c|c|c|c|c|c|c|c|c|c|c|}
\hline \multicolumn{2}{|c|}{$\mathrm{WJZ}=760 \mathrm{kc}$} & \multicolumn{2}{|c|}{$\mathrm{WWU}=338 \mathrm{kc}$} & \multicolumn{2}{|c|}{$\mathrm{WMAL}=630 \mathrm{kc}$} & \multicolumn{2}{|c|}{$\mathrm{WRC}=950 \mathrm{kc}$} & \multicolumn{2}{|c|}{$\mathrm{WJSV}=1,460 \mathrm{kc}$} & \multicolumn{2}{|c|}{$\mathrm{WWV}=290 \mathrm{kc}$} \\
\hline$D$ & $\alpha$ & $D$ & $\alpha$ & $D$ & $\alpha$ & $D$ & $\alpha$ & $D$ & $\alpha$ & $D$ & $\alpha$ \\
\hline $\begin{array}{r}\mathrm{km} \\
25 \\
40 \\
73 \\
90 \\
104 \\
137 \\
170 \\
191 \\
210 \\
240 \\
255 \\
267\end{array}$ & $\begin{array}{l}0.00122 \\
.00147 \\
.00108 \\
.00100 \\
.00102 \\
.000895 \\
.000762 \\
.000693 \\
.000704 \\
.000647 \\
.000647 \\
.000647\end{array}$ & \begin{tabular}{|l}
\multicolumn{1}{c}{$\mathrm{km}$} \\
73.1 \\
97.6 \\
109 \\
142.6 \\
167.6 \\
196.2 \\
214.7 \\
238.3 \\
259 \\
274 \\
\end{tabular} & $\begin{array}{r}0.000417 \\
.000419 \\
.000474 \\
.000396 \\
.000411 \\
.000396 \\
.000425 \\
.000419 \\
.000462 \\
.000458\end{array}$ & $\begin{array}{l}\mathrm{km} \\
11.96 \\
12.8 \\
28.5 \\
48 \\
72.5 \\
93.5 \\
120 \\
145 \\
177 \\
188 \\
211.5 \\
240.5 \\
260 \\
277\end{array}$ & $\begin{array}{l}0.000497 \\
.00133 \\
.00165 \\
.00167 \\
.00116 \\
.00116 \\
.00102 \\
.000915 \\
.000741 \\
.000766 \\
.000681 \\
.000651 \\
.000577 \\
.000583\end{array}$ & $\begin{array}{c}\text { km } \\
4.79 \\
8.1 \\
10.82 \\
12.5 \\
15.43 \\
20.35 \\
22.4 \\
26.5 \\
48 \\
72 \\
92 \\
118 \\
144 \\
177\end{array}$ & $\begin{array}{c}0.00289 \\
.00311 \\
.00163 \\
.00174 \\
.00211 \\
.00208 \\
.00233 \\
.00237 \\
.00186 \\
.00138 \\
.00122 \\
.00101 \\
.000901 \\
.000768\end{array}$ & $\begin{array}{l}k m \\
.3 .07 \\
8.05 \\
12.03 \\
15.35 \\
18.1 \\
22.8 \\
32 \\
48 \\
68.5 \\
97.5 \\
113 \\
138\end{array}$ & $\begin{array}{l}0.000318 \\
.00275 \\
.00244 \\
.00195 \\
.00231 \\
.00225 \\
.00230 \\
.00169 \\
.00136 \\
.00106 \\
.000947 \\
.000855 \\
. . .\end{array}$ & $\begin{array}{l}\mathrm{km} \\
37.5 \\
60.4 \\
81 \\
107 \\
132.6 \\
165.2 \\
176 \\
199 \\
228 \\
247.5 \\
264 \\
\\
\end{array}$ & $\begin{array}{r}0.000433 \\
.000156 \\
.000251 \\
.000365 \\
.000335 \\
.000193 \\
.000233 \\
.000159 \\
.000202 \\
.000254 \\
.000295 \\
\end{array}$ \\
\hline
\end{tabular}


For path No. 1 the WJZ attenuation factors were plotted and one of Rolf's graphs was fitted to them, thus determining the average conductivity and dielectric constant for path No. 1. Rolf's $10^{\circ}$ graph was found to fit satisfactorily after the correction (see equation (4) of Rolf's Proc. I. R. E. paper) for the earth's curvature was made; see solid line graph marked $760 \mathrm{kc}$ in Figure 11. The dotted graph just above shows the $10^{\circ}$ graph before the earth's curvature correction was made. The dielectric constant was determined to be 13 by means of Rolf's abac. The conductivity was then determined to be $3.35 \times$ $10^{-14}$ e. m. u. by means of equation (1) of Rolf's paper. These values of dielectric constant and conductivity were considered as average values for the whole path and determine the attenuation factor

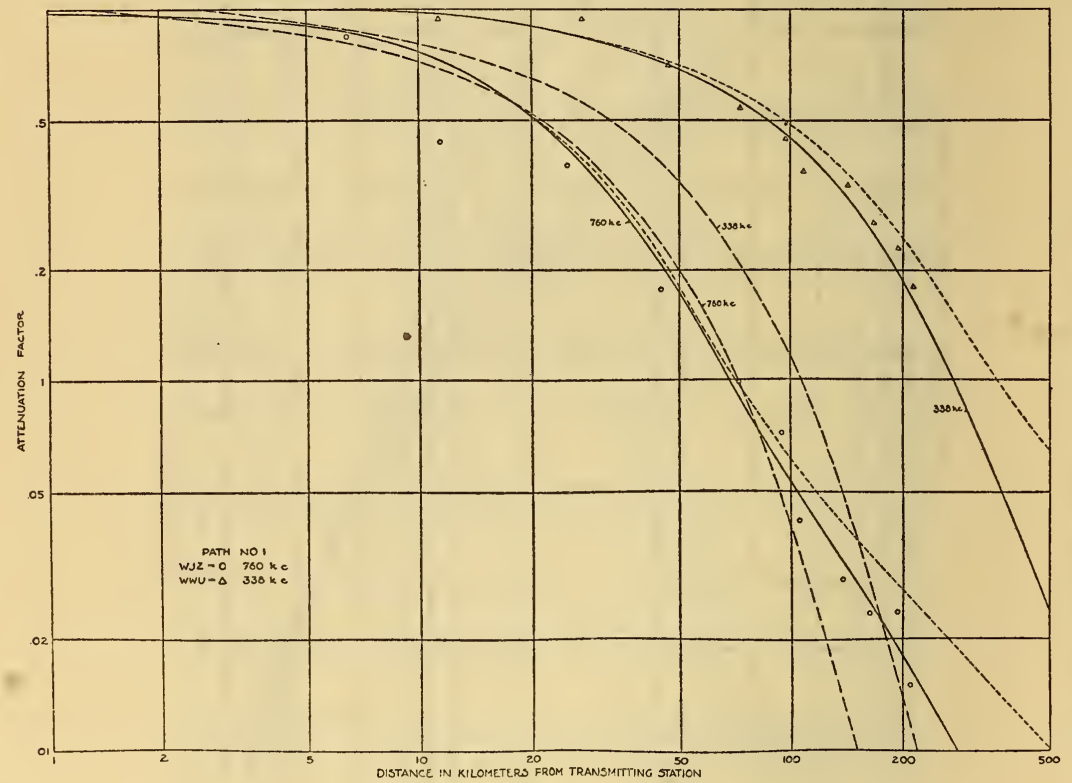

FIGURE 11.-Attenuation factors versus distance

Experimental results are shown by the points plotted. Rolf's theoretical graphs corrected for curvature of the earth are shown by the solid lines. Rolf's graphs uncorrected for curvature of the earth are shown by the short dashed lines. Graphs with long dashes represent the Austin-Cohen formula plotted with the average $a$ of Table 2.

graphs for any other frequency over the same path. The theoretical graph for $338 \mathrm{kc}$ is also plotted in Figure 11, the dotted graph just above showing Rolf's graph for that frequency, dielectric constant, and conductivity before correction is made for the curvature of the earth. Theoretical graphs for the other frequencies measured over this path are given in Figure 12 for these same values of dielectric constant and conductivity. It should be noted that when Rolf's theoretical graph for $760 \mathrm{kc}$ was selected the theoretical graphs for the other frequencies over path No. 1 were automatically determined. Over this path the extreme error given by any graph was 48 per cent of the measured value. Usually the discrepancies between the measured values and the graphs were much less than this. Considering the point to point variability of the path, the possibilities of variations of transmitting antenna current, together with the possibility of small 
errors in the measurements, it is believed that the agreement between measurement and theory is very good.

For path No. 2 the WRC attenuation factors were used to determine the dielectric constant and conductivity which were found to be $\epsilon=12, \sigma=3.22 \times 10^{-14}$ e. m. u. The theoretical graphs were then drawn in Figure 13 for the three frequencies measured over this path. Attenuation factors of transmissions over path No. 2 from KDKA, $980 \mathrm{kc}$, were plotted in this figure although the west end of the path was quite mountainous while the eastern end was rolling land. The attenuation factors were found to fit very well the $950 \mathrm{kc}$ graph for this path. Thus the absorption over the mountains was no greater than over the land east of the mountains for corresponding frequencies. In general, the locations at which field-intensity measurements were made in the mountains were selected in open spaces so as to eliminate

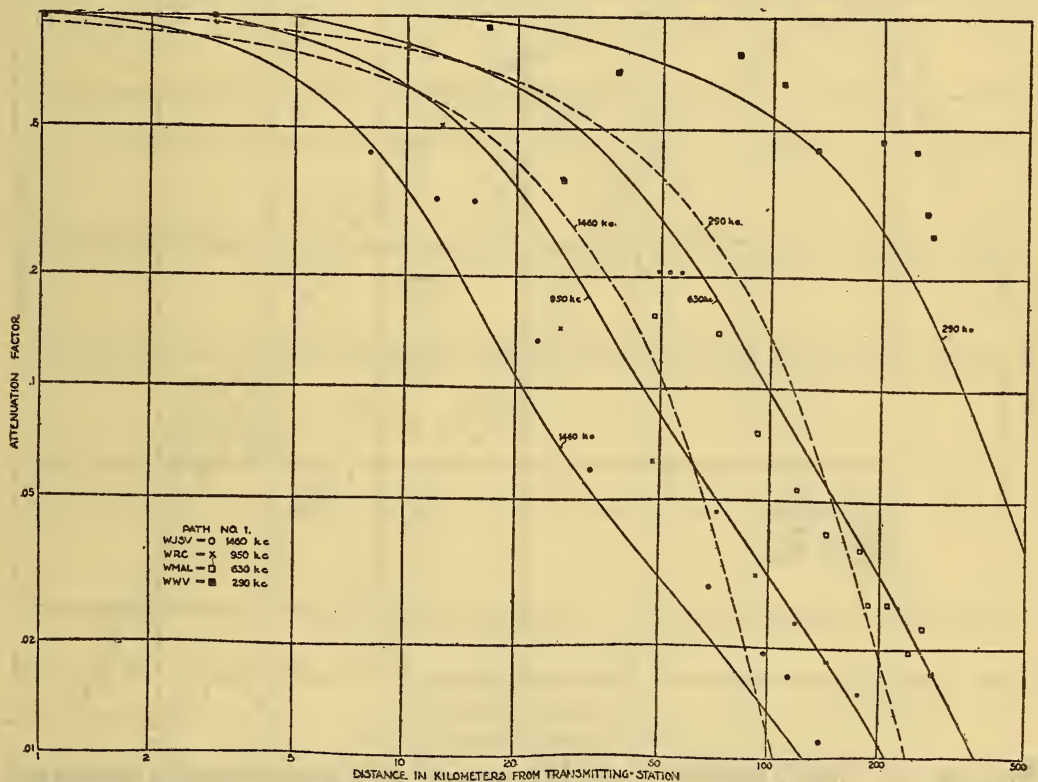

FIGURE 12.-Attenuation factors versus distance

Experimental results are shown by the points plotted. Rolf's theoretical graphs corrected for the curvature of the earth are shown by the solid lines. The dashed graphs represent the AustinCohen-formula plotted with the average $a$ of Table 2 .

as far as possible any local shadow effects. However, in two cases this was not done. In a deep valley (Turtle Creek) east of Pittsburgh and about $200 \mathrm{~km}$ from Cleveland, WWO's transmission on 344 kc measured less than half the normal value. (Fig. 7.) In this same location WTAM on $1,070 \mathrm{kc}$ measured just about normal. On the east side of and halfway up a mountain at a distance of about $280 \mathrm{~km}$ from Cleveland, WWO's transmission measured about 25 per cent below normal while WTAM's transmission was again nearly normal. (Fig. 8.)

For path No. 3 the WTAM attenuation factors were used to determine the dielectric constant and conductivity which were found to be $\epsilon=12, \sigma=7.75 \times 10^{-14}$ e.m.u. This path was not uniform (see fig. 14) as it was mountainous at the east end and fairly flat at the 
west end. The transmissions were not absorbed so much over the western part of this path as over the eastern part (probably due to a lower conductivity at the eastern end rather than the mountains, since path No. 2 showed no greater absorption than path No. 1); this caused the more distant WTAM and WWO points to fall below their respective graphs. The measured attenuation factors for KDKA on this path were also plotted. No theoretical graph was drawn, however, since the path from KDKA west was not thought to be similar to that from Cleveland east. It may be noted that the attenuation factors which were obtained in the mountains lie below the $1,070 \mathrm{kc}$ graph while those that were obtained near Cleveland lie above this graph, thus indicating a different type of ground conditions (conductivity) in the mountains than those near Cleveland.

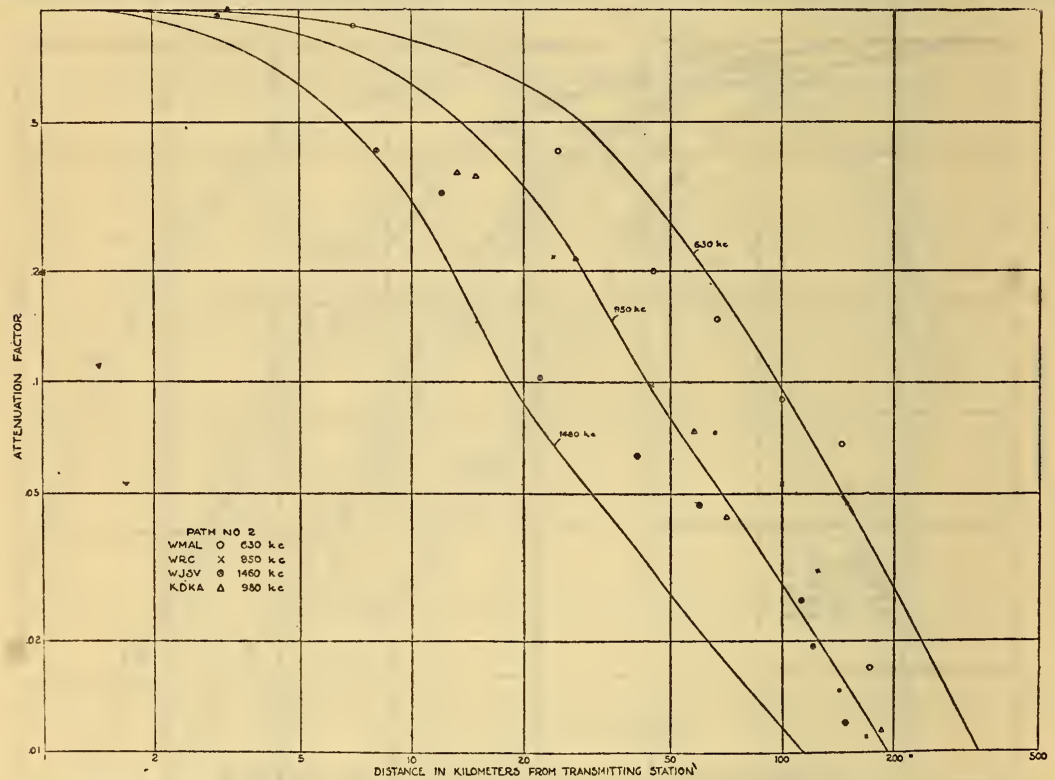

FIGURE 13.-Rolf's theoretical graphs compared with experimentally determined attenuation factors

For path No. 4 the WGN attenuation factors were used to determine the dielectric constant and conductivity which were found to be $\epsilon=13, \sigma=1.07 \times 10^{-13}$ e.m.u. It is easily seen in Figures 15 and 16 that the various frequencies measured over this path are not absorbed as much as corresponding frequencies over paths Nos. 1 and 2. The authors believe that this difference is due almost entirely to the difference in the radio-frequency conductivity of the two paths and not so much to the fact that path No. 4 is over more level ground. The fact that the land for paths Nos. 1 and 2 is more wooded ${ }^{4}$ than the others might lead to lower values of the conductivity there.

In order to provide a convenient means of estimating the field intensity of the ground wave for any frequency in the broadcast band and for paths east or west of the west side of the Alleghenies, 
in the latitudes covered by these measurements, graphs are drawn in Figure 17 giving the field intensity versus distance for 300,600 , 1,000 , and 1,400 kc. Using the conductivity and dielectric constant as determined for path No. 1, Rolf's graphs were used to determine the proper attenuation factors for the above frequencies east of the Alleghenies (paths Nos. 1 and 2); for the frequencies west of the Alleghenies, the conductivity and dielectric constant as determined for path No. 4 were used. These graphs were drawn for an assumed radiated power of about $11 \mathrm{kw}$, which corresponds to a field intensity of $10^{6} \mu v /$ meter at a distance of $1 \mathrm{~km}$ from the transmitting station.

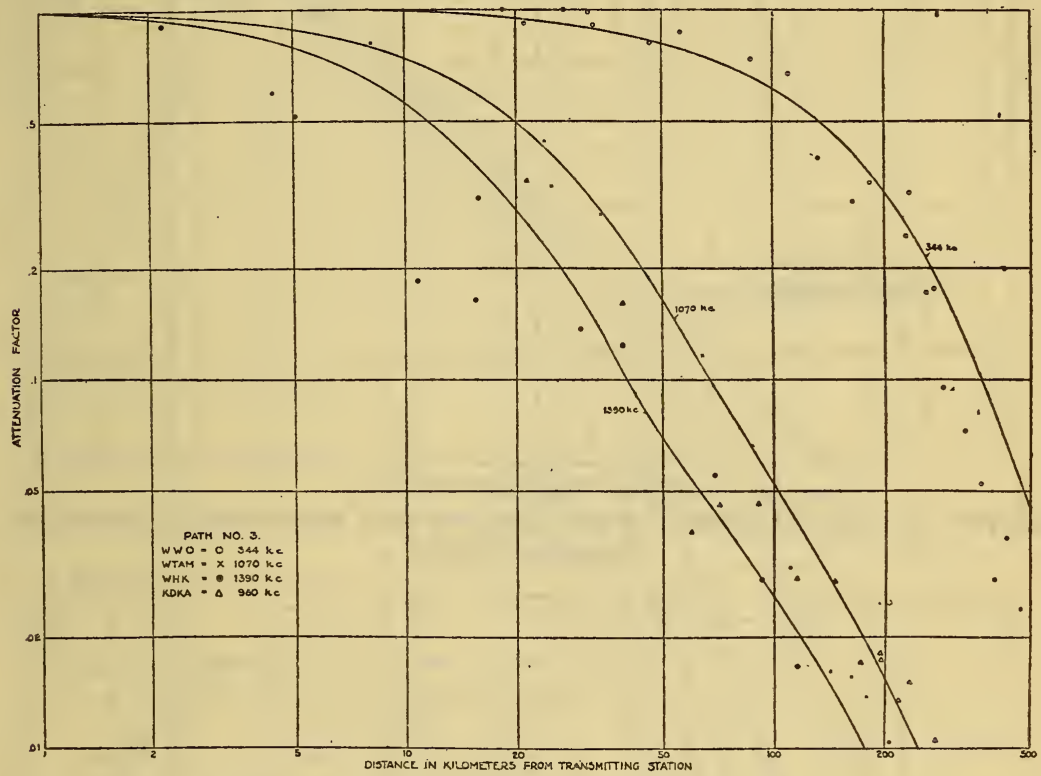

FIGURE 14.- Rolf's theoretical graphs compared with experimentally determined attenuation factors

For any other radiated power $P_{r}$ given in kilowatts, the given field intensities must be multiplied by a factor

$$
K=0.3 \sqrt{P_{r}}
$$

It should be noted at this point that the radiated power is always somewhat lower than the power input to the antenna and for frequencies in the broadcast band the radiated power is usually less than half the rated power. If field-intensity measurements have been made near the transmitting station the radiated power may be approximately determined by means of the formula ${ }^{5}$ where

Radiated power $=P_{r}=(F D / 3 A)^{2} 10^{-10}$ kilowatts

$F=$ field intensity in microvolts per meter.

$D=$ distance from transmitting station in kilometers.

$A=$ attenuation factor.

The attenuation factor to be used may be determined for any given path, frequency, and distance from Figures 11 to 16 , inclusive. Thus in order to determine the daytime (ground wave) field intensity

\footnotetext{
S Pierce, Electrical Oscillations and Electric Waves, ch. 9.
} 
in any direction and at any distance from the transmitter for broadcasting stations east of Chicago it is merely necessary to make a

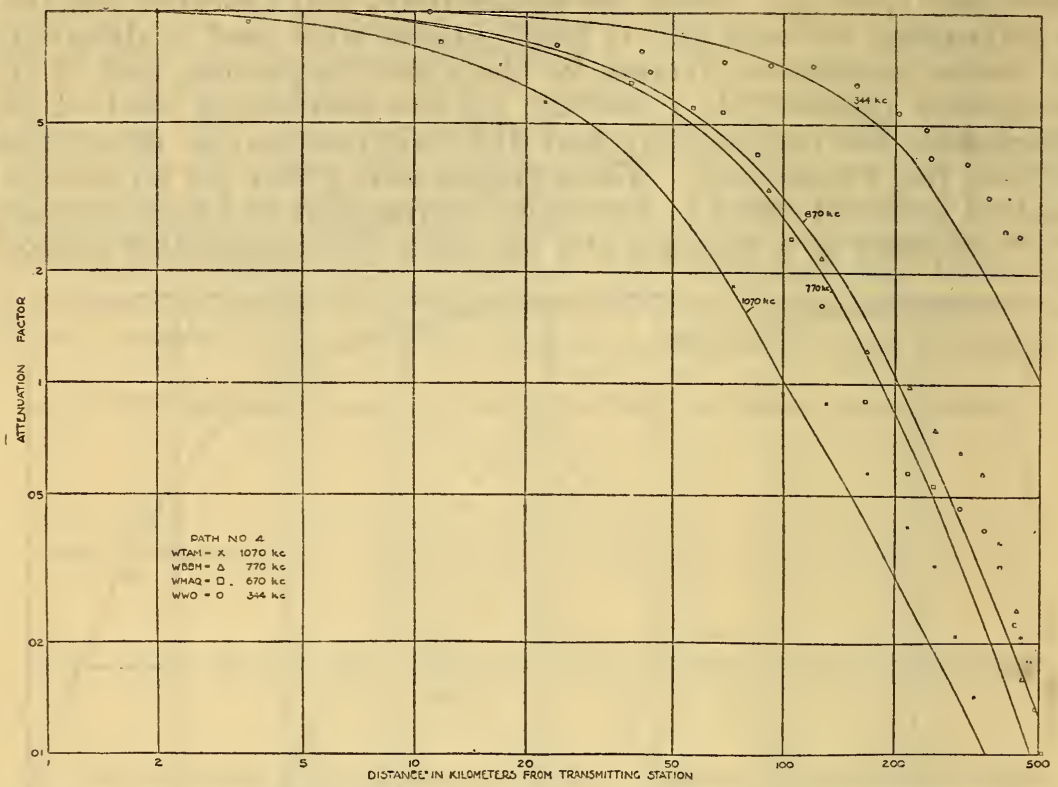

FIGURE 15.-Rolf's theoretical graphs compared with experimentally determined attenuation factors

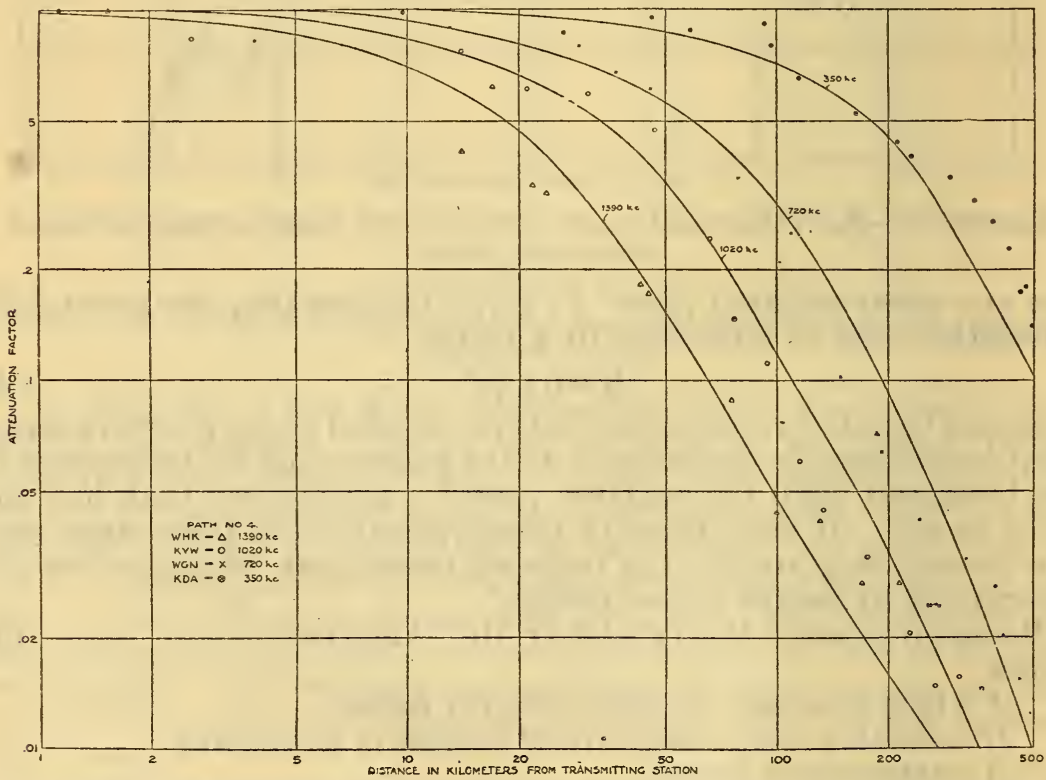

FIGURE 16.-Rolf's theoretical graphs compared with experimentally determined attenuation factors

single measurement of the field intensity in the direction from the transmitting station in which other values are to be estimated. This, together with the value of $A$ as determined from the graphs assuming 
the constancy of the ground conductivity with time, ${ }^{6}$ may be substituted in equation (5) to give the power radiated in that direction. The factor $K$ may then be determined from equation (4); this factor

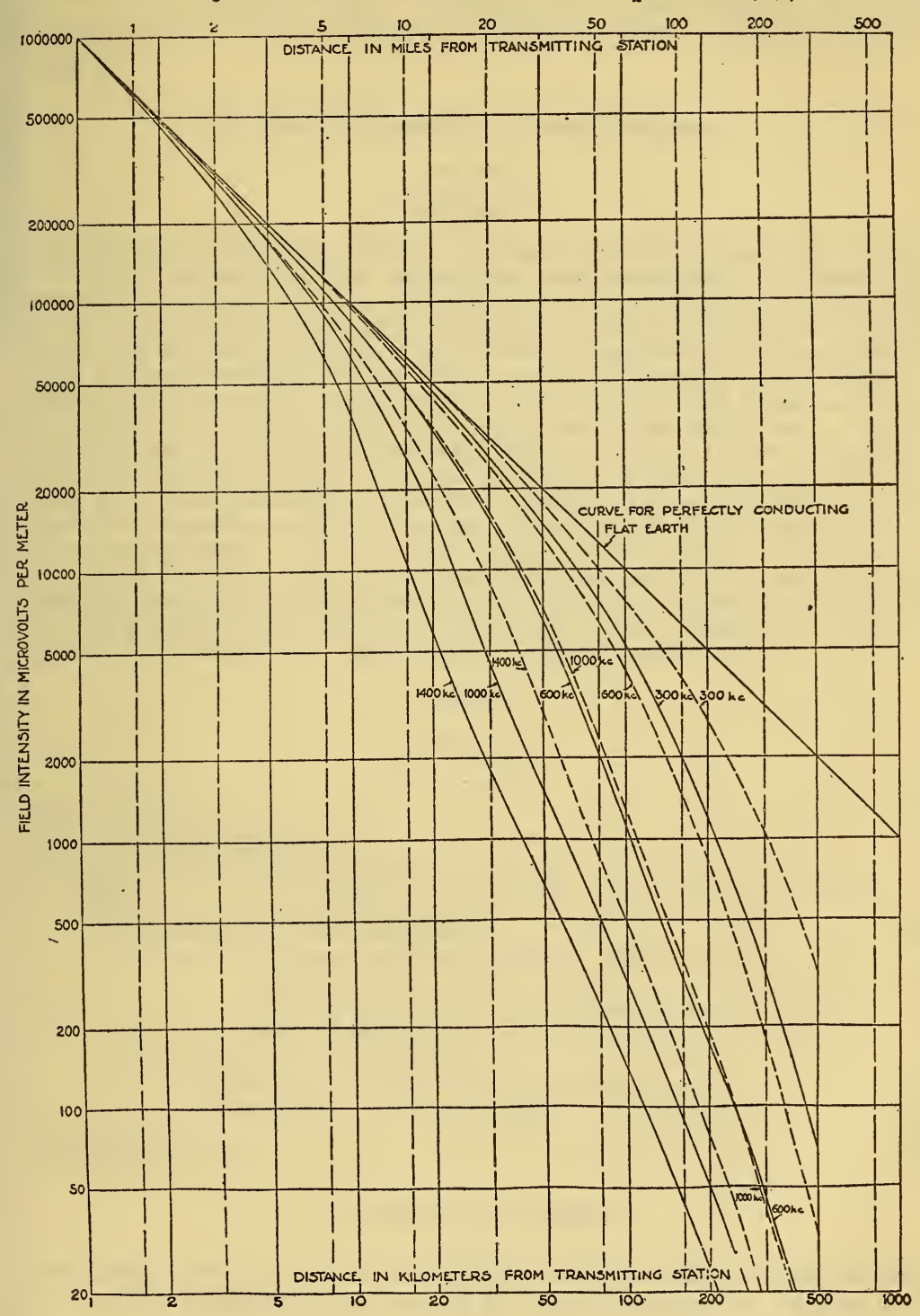

FIGURE 17.-Field intensity versus distance

Solid graphs predict the field intensity of the ground wave for $\epsilon=12 \sigma=3.22 \times 10^{-14}$ e.m.u. paths Nos. 1 and 2. Dashed graphs predict the field intensity of the ground wave for $\epsilon=13 \sigma=1.07 \times 10^{-18}$ path 4. Radiated power assumed as $11 \mathrm{kw}$.

when multiplied by the field intensities in Figure 17 gives the required field intensity.

WASHington, January 19, 1932.

6 Continuous automatic field intensity records of transmissions from WJZ (760 kc), Bound Brook, N. J. over a path $275 \mathrm{~km}$ long show total variations of daytime field intensities of about 30 per cent over a period of a year. 